\title{
port@l.eletrônico.gov
}

\section{CONSIDERAÇÕES SOBRE A INTERAÇÃO SOCIEDADE-ESTADO ATRAVÉS DAS REDES TELEMÁTICAS ${ }^{1}$}

\author{
ESTER LIMONAD \\ Universidade Federal Fluminense \\ RAINER RANDOLPH \\ Instituto de Pesquisa e Planejamento Urbano e Regional \\ Universidade Federal do Rio de Janeiro
}

O presente ensaio tem como objetivo proceder a uma leitura crítica do papel e significado do governo eletrônico na atualidade, especialmente em relação à superação (ou aprofundamento) de divisões sociais e espaciais ${ }^{2}$ existentes nas sociedades contemporâneas.

A importância da temática expressa-se na difusão cada vez maior na internet de páginas web (websites, homepages) governamentais tanto ao nível nacional, regional (estadual) como local (municipal) em quase todos os países do mundo.

Apresentaremos a nossa argumentação em três passos principais: em um primeiro momento caracterizamos, de forma descritiva, os principais elementos e constituintes do próprio objeto de nosso ensaio: o e-governo (i). Em um segundo momento serão explicitadas as formas de disseminação desta proposta do e-governo, tanto no mundo como, em particular, no Brasil (ii). Finalmente, faremos um primeiro esboço da nossa perspectiva a respeito deste objeto a partir de uma reflexão crítica das suas características e proposições (iii).

Em todos estes momentos será conferida atenção especial à relação entre as propostas e as características do e-governo e a questão do fortalecimento da sociedade (civil) enquanto uma forma de combater o digital divide em sociedades já tão segmentadas como a nossa. Faremos isto na medida em que entendemos que essa problemática não pode ser reduzida meramente à questão do acesso à tecnologia e às redes telemáticas.

Inicialmente nos dedicaremos às seguintes perguntas: o que é o e-government e como se dissemina? Procuraremos caracterizar o que pode ser entendido como e-governo ou governo eletrônico (e-government) e apresentar o fenômeno da sua disseminação exponencial.

Em recentes análises, realizadas no âmbito do lançamento do Programa "Sociedade da Informação" pelo governo federal brasileiro, foi identificado "um cenário preocupante" relativo ao desenvolvimento e utilização de produtos e serviços avançados de computação no país,

1 Esta é uma versão revista e ampliada de um ensaio apresentado no XIII Congreso de la Asociación Latinoamericana de Sociología (ALAS), realizado na Universidad de San Carlos, Guatemala, República de Guatemala, de 29 de outubro a 2 de novembro de 2001.

2 Questões relativas à segregação sócio-espacial não serão abordadas aqui explicitamente; isto pressuporia uma preparação maior com relação à compreensão de espaço e de lugar como elaborado, por exemplo, em Limonad e Randolph, 2000. 
conforme indicam os seguintes dados: se na União Européia, todas as escolas públicas estarão interligadas em rede até 2003 e nos EUA, nesse mesmo ano, mais de $75 \%$ da sua população será usuária da Internet, no Brasil menos de 1.000 das 4.300 bibliotecas públicas (não há sequer uma biblioteca para cada município) estão ligadas à Internet e, segundo uma avaliação da Câmara Americana de Comércio, "se nada for feito, o país chegará a 2003 com mais de 100 milhões de analfabetos digitais".

Segundo uma pesquisa ${ }^{3}$ realizada, em 1997, pelo grupo de tecnologia do G7, os governos têm utilizado a Internet basicamente para a disseminação de informações. Em 1994, nenhum país dispunha de sites governamentais; atualmente a maioria tem portais centralizados de informações e serviços diversos on-line - que abrangem desde informações sobre concursos, licitações, horários e trajetos de ônibus, exigências para tirar documentos, até serviços de fato como emitir formulários e guias de pagamento, pagar tributos on-line e declarar o imposto de renda ${ }^{4}$. Este conjunto de serviços e informações disponibilizados na Internet faz parte do que se convencionou chamar de e-government, ou governo eletrônico.

Nos Estados Unidos, o portal www.firstgov.gov permite ver desde concursos, licitações, oportunidades de empregos públicos até levantamentos de dados macroeconômicos. A Internet é utilizada para fazer estimativas do valor de aposentadorias, liberar carteiras de seguro social e marcar consultas. Portais centralizados de serviços para os cidadãos foram criados pelos governos da Grã-Bretanha (www.ukonline.gov.uk). e de Cingapura (www. ecitizen. gov. sg) - neste último há o desenho de um caminho que leva a pessoa do registro de um nascimento à aposentadoria. Este site reúne oito distintas áreas (negócios, defesa, educação, emprego, saúde, habitação, legislação e transportes) e foi apontado por uma pesquisa feita pela Administração Geral de Serviços dos Estados Unidos como o mais eficiente site de e-governo do mundo. Em Israel, propostas a serem votadas no Legislativo são disponibilizadas na Internet para comentários. No Brasil o portal www.redegoverno.gov.br disponibiliza uma série de serviços e ligações com sites federais, estaduais e municipais. Além disso, em outubro de 2001 o Brasil realizou a maior eleição eletrônica do mundo: no primeiro turno, com a participação de 109 milhões de eleitores, $o$ resultado saiu em 29 horas. No segundo turno 26,5 milhões de pessoas votaram em 31 cidades. (http://www.uol.com.br/negociosexame/complementos/revista0003_2c.html).

Uma breve pesquisa na rede permitiu-nos concluir que, nos últimos sete anos, os sites governamentais multiplicaram-se exponencialmente mundo afora, e pode-se dizer que isto contribuiu para: a) minar a burocracia na relação entre os poderes públicos e a sociedade; b) reduzir os custos governamentais com mão de obra, papel, tinta e tramitações ${ }^{5}$; c) tornar mais transparentes as ações do Estado; d) prover serviços de maneira mais eficiente; e) tornar os lugares mais competitivos, f) combater a corrupção e, enfim, democratizar o acesso à informação. Isto faz com que os apóstolos do e-government apregoem uma nova era de transparência e democratização no acesso aos serviços públicos, principalmente nos chamados países em desenvolvimento.

Trataremos de desenhar, a seguir, um quadro geral da extensão do e-government no Brasil, para então assinalar algumas tendências que se esboçam e que tendem a conformar um novo tipo de exclusão: a digital (para uma discussão acerca dos casos de Buenos Aires e Montevidéu, vide Finquelievich, 2001). Foi levantada uma série de dados e características junto aos portais governamentais da qual trataremos resumidamente.

O Brasil possui mais de 3500 sites governamentais. De acordo com a Fundação de Amparo à Pesquisa do Estado de São Paulo (FAPESP), responsável pelo registro de domínios na

3 O levantamento foi feito em dezesseis países: Alemanha, Austrália, Canadá, Coréia do Sul, Estados Unidos, Finlândia, Hungria, Irlanda, Israel, Japão, Malta, Noruega, Nova Zelândia, Portugal, Reino Unido e Suécia (Revista Update, 367, dezembro de 2000)

4 No Brasil, segundo a Receita Federal, no ano de 2001, 84\% dos contribuintes apresentaram a declaração do imposto de renda pela Internet, enquanto em 1996 apenas $6 \%$ o fizeram.

5 No Canadá, a tecnologia de informação contribuiu para eliminar 89 mil empregos públicos. 
Internet no Brasil, há pelo menos 572 matrizes de endereços estaduais e federais sob o domínio gov.br no país e cada matriz pode ter mais de um site. O governo federal dispõe de pelo menos setecentos sites, com mais de um milhão de páginas, setecentos serviços on-line e mais de quatro mil e cem informações catalogadas. Todos os vinte e sete governos estaduais possuem homepages, dos quais metade possui serviços on-line - a maioria voltada para a emissão de guias de pagamento e recolhimento de impostos, taxas e multas.

Uma pesquisa do Instituto Florestan Fernandes, realizada em 2000, localizou 352 sites municipais (o equivalente a $6,3 \%$ das 5.507 cidades brasileiras), mas apenas $5,4 \%$ destes sites permitem o acesso a serviços on-line; o restante disponibiliza informações sobre as exigências, procedimentos e trâmites necessários para os serviços requisitados. Um levantamento que realizamos na rede, durante o ano de 2001, constatou que $2 / 3$ das capitais e $7 \%$ dos municípios brasileiros apresentam serviços on-line, todavia a maioria apenas divulga informações e somente um reduzido número apresenta uma diversidade de serviços, geralmente voltados para a cobrança e recebimento de impostos. Ainda segundo um diagnóstico do governo federal "o Portal Rede Governo na Internet já oferece 629 serviços e 3.500 informações, mas é possível constatar que a oferta de serviços ainda é concentrada em poucos órgãos" ("Proposta de Política de Governo Eletrônico para o Poder Executivo Federal" in http://www. governoeletronico. gov. br).

Pelo mapa, na página seguinte, pode-se notar que as capitais estaduais com serviços online em maior quantidade encontram-se nas regiões Sul e Sudeste - as mais desenvolvidas do Brasil, com alguns casos isolados nas outras regiões. O mesmo se verifica em relação aos serviços on-line disponibilizados pelos governos estaduais com algumas exceções como os casos da Bahia, Maranhão, Goiás e Rio Grande do Norte.

capitais com e-governo

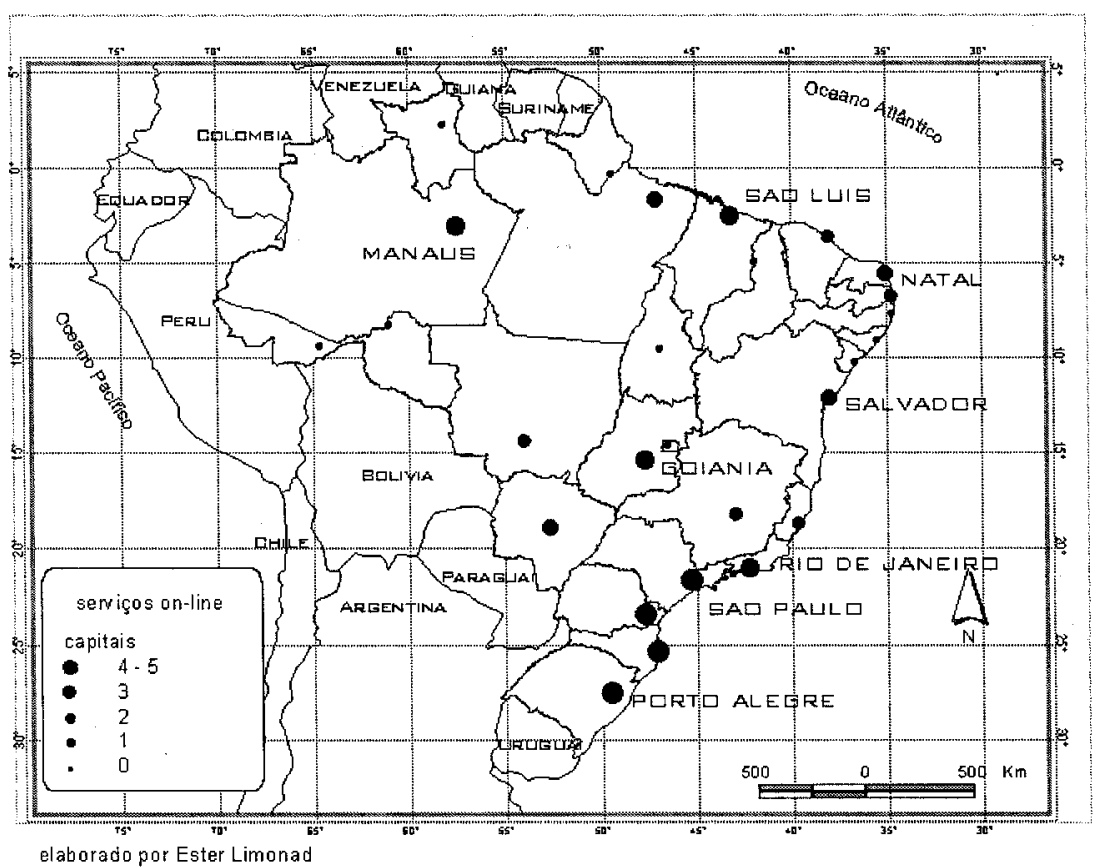

Se a multiplicação de sites governamentais contribuiu para ampliar a interface de relacionamento de prestação de serviços do Estado com os cidadãos, isto não pode ser generalizado, ao menos em boa parte do mundo e mesmo no Brasil. Sem dúvida a exclusão social todavia perdura, em uma nova forma: a digital, pois ainda são poucos os que têm acesso à rede e sabem como utilizá-la. A Internet contribui para aprofundar a exclusão social, especialmente se lembrarmos que no Brasil apenas $5 \%$ da população goza deste acesso, o que não inclui os que 
mais necessitam da ação do governo, como pobres, menos instruídos e idosos. Ademais muitas pessoas, além de não terem computador e não saberem como operá-lo, não dispõem de conta corrente em banco - o que impede sua utilização plena da rede.

Temos, assim, um digital divide social e espacial que impõe a premência de democratizar o acesso à Internet (RANDOLPH e LIMA, 2000). Tal premência é diagnosticada principalmente pelo governo e empresários interessados em aumentar a competitividade e inserir o país na corrida global. Caso contrário teremos a ampliação da exclusão digital com um cresçente número de analfabetos digitais e de localidades excluídas - pois na era da informação quem não está conectado, não existe para o resto do mundo em termos de investimentos e oportunidades. Se antes a regionalização e apropriação territorial faziam-se horizontalmente hoje isto ocorre verticalmente (SANTOS, 1996), através das redes virtuais de telecomunicação.

A utilização da Internet pelo setor público, além de permitir reduzir custos - como ocorre no setor privado - possibilita o acesso à informação. Todavia, apesar da disponibilidade $\mathrm{e}$ acessibilidade digital, devemos lembrar que no Brasil, nona economia mundial, a telefonia fixa ainda é um artigo de difícil aquisição, e a média de usuários da Internet está muito aquém da média de $15,4 \%$ registrada pelas 10 maiores economias mundiais (http://www.amcham.com.br/revista/367). Média esta, também, não muito elevada em termos "globais" se considerarmos que "o mundo hoje tem 6 bilhões de pessoas, 4,8 bilhões das quais vivem em países em desenvolvimento. Segundo o Banco Mundial, 4,2 bilhões de habitantes vivem com menos de US\$ 2 por dia. Nos próximos 25 anos a população mundial deve passar de 6 para 8 bilhões e $97 \%$ estarão nos países em desenvolvimento". (http://www.amcham.com.br/revista/367).

Entre um dos principais objetivos do governo federal nas áreas de informação e prestação de serviços públicos, expresso na proposta de implantação do governo eletrônico (http://www.governoeletronico. gov. br), está a universalização do acesso à Internet. Com este propósito temos a implantação de Pontos Eletrônicos de Presença (PEPs) em vários órgãos da administração federal espalhados pelo país; através dos quais qualquer pessoa pode entrar na internet e utilizar os serviços oferecidos pelo governo federal on-line.

Falar da realidade brasileira (uma realidade) é bastante questionável, na medida em que as condições são tão mais controversas e heterogêneas entre diferentes regiões e mesmo cidades do país, o que exige muita cautela, em princípio, quando se procura comparar o país com as experiências verificadas nos países industrializados (ou propostas elaboradas).

\section{II}

Vamos, então, observar algumas características e propostas concretas. Segundo diversas firmas de consultoria empresarial o problema são as pessoas que não têm computador, não sabem como operá-lo e sequer têm conta corrente em banco. Se não houver consumidores em condições de usufruir o comércio eletrônico, tornar-se-á mais difícil para o Brasil aumentar sua presença no comércio globalizado, e ainda segundo estas firmas, para os países se tornarem competitivos no mercado internacional devem adotar portais de governo eletrônico. Isto explica a integração desta plataforma nas proposições do "Avança Brasil” (http://www.brasil.gov.br), segunda etapa do plano estratégico do governo neoliberal para a inserção competitiva do Brasil no panorama mundial.

A face mais alardeada do governo eletrônico é a democratização do acesso aos serviços públicos, porém isto só se aplica a quem tem acesso à Internet. Se na Finlândia, país de ponta quando se trata de informática, qualquer transeunte tem acesso gratuito em terminais localizados em bibliotecas; no Brasil menos de um quarto das bibliotecas públicas estão ligadas à Internet, e nem todas os municípios dispõem de bibliotecas e sequer de telefone. 
A interface eletrônica governo-cidadão (denominada em diversos estados brasileiros de SAC - Serviço de Atendimento ao Cidadão) contribuiria, em última instância, para reduzir a distância entre as pessoas e ampliar o acesso e a qualidade da informação. E neste sentido que a "Proposta de Política de Governo Eletrônico para o Poder Executivo Federal" (http://www.governoeletronico.gov.br) tem entre outras metas "a interiorização dos serviços de governo, a partir da instalação de pontos eletrônicos de presença (PEP's), compartilhados entre os diversos órgãos em localidades que estejam desprovidas de qualquer infra-estrutura de informações governamentais". Aí se insere a proposta de disponibilização de um PEP em cada órgão público e o projeto piloto de atendimento a pequenas localidades e postos de fronteira com um pacote de serviços e informações nas áreas de educação, saúde, previdência social, trabalho, segurança e direitos humanos, através do portal Rede Governo.

A instalação de PEPs ajudaria bastante a democratizar o acesso à rede. Como as informações estão em rede, um ponto de atendimento resolve vários problemas - evitam-se filas, carimbos, vistos e autorizações. Os PEPs têm por base a idéia de "one stop government", de atendimento integrado ao cidadão, encontrada hoje em diversos estados brasileiros, cujos pioneiros foram o Poupatempo de São Paulo, o SAC da Bahia (vide SANTOS, 2001), o Psiu de Minas Gerais e a Rua da Cidadania em Curitiba. Tal iniciativa mostra que não é necessário ter uma linha de Internet em casa para sentir os efeitos do governo eletrônico. Entretanto, em todos esses casos, quem opera o computador é um funcionário público. A alfabetização digital permitiria que os próprios cidadãos conseguissem resolver seus problemas na frente de um computador. Para isso, a implantação de computadores deve ser acompanhada de programas que ensinem a população a operar um micro e a usar a Internet, a começar pelas escolas.

A Casa Civil da Presidência da República criou, em abril de 2000, um grupo de trabalho interministerial com a finalidade de examinar e propor políticas, diretrizes e normas relacionadas com as novas formas eletrônicas de interação. Esse grupo ficou conhecido como Grupo de Trabalho em Tecnologia da Informação - GTTI e suas ações coadunaram-se com as metas do Programa Sociedade da Informação, coordenado pelo Ministério da Ciência e Tecnologia. Por orientação do governo, o trabalho do GTTI, inicialmente, concentrou esforços em três das sete linhas de ação do Programa Sociedade da Informação:

a) universalização de serviços - trata-se de através de soluções alternativas com base em novos dispositivos e novos meios de comunicação, promover modelos de acesso coletivo ou compartilhado à Internet; e fomentar projetos que promovam a cidadania e a coesão social;

b) governo ao alcance de todos - promover a informatização da administração pública e do uso de padrões nos seus sistemas aplicativos; bem como a concepção, prototipagem e fomento às aplicações em serviços de governo, especialmente os que envolvem ampla disseminação de informações; fomento à capacitação em gestão de tecnologias de informação e comunicação na administração pública; e

c) infra-estrutura avançada - trata-se da implantação de infra-estrutura básica nacional de informações com a integração das diversas estruturas especializadas de redes - governo, setor privado e $\mathrm{P} \& \mathrm{D}$; adoção de políticas e mecanismos de segurança e privacidade; fomento à implantação de redes, de processamento de alto desempenho e à experimentação de novos protocolos e serviços genéricos; transferência acelerada de tecnologia de redes do setor de $\mathrm{P} \& \mathrm{D}$ para as outras redes e fomento à integração operacional das mesmas.

Em continuidade aos trabalhos do GTTI, em outubro de 2000 foi criado o Comitê Executivo do Governo Eletrônico (e-Gov), cujo documento básico de trabalho é a "Proposta de Política Para o Governo Eletrônico" que estabelece quarenta e cinco metas diversas. Se uma parte destas metas se concretizar, o Brasil chegará em 2003 passos à frente do que se espera do 
crescimento inercial projetado por firmas de consultoria internacional. A perspectiva é de que em 2003 haja 250 mil computadores ligados à Internet em locais públicos, entre os quais se contam a interligação de todas as bibliotecas públicas, não só as administradas pelos poderes públicos, mas também as de ONGs abertas às comunidades; a abertura de quiosques para uso da população, pontos de acesso nas agências de Correios e do Banco do Brasil. Além disso, deverão ser incrementadas as compras on-line do governo federal previstas para 2001 (ComprasNet), o que deverá impulsionar o ingresso de empresas fornecedoras de produtos e serviços para o governo na rede. Há que se considerar ainda a intenção da Receita Federal de, também no próximo ano, permitir o pagamento de impostos e taxas pela Internet. Só o fato de o governo juntar todas as iniciativas de órgãos e ministérios num só programa já fará com que o gasto com telecomunicações caia pela metade — o que representa milhões de reais.

\section{III}

$\mathrm{Na}$ discussão sobre o e-governo encontramos uma diferenciação que diz respeito ao grau do envolvimento dos distintos agentes na apropriação das tecnologias de informação e comunicação. Passando de uma maneira mais fechada, em um sentido simples, do uso das novas tecnologias pelos governos chega-se às formas mais sofisticadas que envolvem não apenas o relacionamento entre governo e sociedade, mas inclusive os relacionamentos de cidadãos para cidadãos.

Há, primeiro, uma tradição já mais antiga, desde o uso da informática nas próprias repartições públicas, de racionalização interna das tarefas e operações governamentais. Mesmo as mais recentes tecnologias telemáticas e redes de computadores contribuem assim para a transformação da administração pública nos seus aspectos de eficácia e eficiência internas através de programas de descentralização, deslocamento, terceirização etc. Tendencialmente a discussão a respeito do e-governo não está voltada para este nível de apropriação.

Um segundo patamar busca focar a relação e interface entre governo e cidadão, ou usuário ou cliente (cada um destes termos traz conotações distintas). Como vimos na rápida apresentação de alguns exemplos, o debate gira em torno do fornecimento de serviços por parte do governo, da acessibilidade aos governantes, da transparência da ação governamental, da demanda por parte dos clientes (cidadãos) e sua eficaz e eficiente satisfação etc.

Já no terceiro patamar, o governo, através de uma rede telemática de computadores, sustentaria uma nova plataforma para articulações entre cidadãos e fortaleceria, assim, a democracia participativa.

Para a maioria das propostas, o e-governo (e-government) deve buscar uma maior aproximação entre "Governo" e "sociedade" — segundo patamar - através da oferta de determinados serviços públicos do primeiro ao último cujo acesso pode ser facilitado por meio da utilização das novas tecnologias telemáticas e redes de computadores. A participação cívica na expressão das necessidades sociais e a formulação de uma demanda por serviços são consideradas elementos importantes para a implantação bem sucedida dessa estratégia.

Um outro critério são os próprios serviços e suas potencialidades em termos de sua "interatividade" oferecidos por "via eletrônica". Diante destas experiências e, na maioria das vezes, propostas de implantação deste e-governo, costuma-se falar, particularmente em círculos próximos aos entusiastas das novas tecnologias de telemática e redes de computadores, do surgimento de uma nova "relação" ou mesmo interação" entre sociedade civil e Estado originado nas e impulsionado pelas tecnologias. As abordagens predominantemente pragmáticas têm pouca preocupação com alguma compreensão mais profunda a seu respeito.

O "novo" justifica-se não exclusivamente pela difusão dessas tecnologias, mas também por causa da implantação de propostas políticas (despolitizantes) nos últimos anos que ou 
produziram o discurso pós-corporativista do planejamento estratégico ${ }^{6}$ do Estado ou uma pretensa reviravolta pós-capitalista da organização de uma parte da sociedade civil no assim chamado Terceiro Setor. Em poucas palavras: o setor público - os governos locais em particular "avança" em direção ao empresariamento da gestão e o setor privado assume, crescentemente, responsabilidades sociais - dois mundos ao avesso que, na aparência, transformam antigos conflitos e antagonismos em paralelos que, senão aqui e agora, supostamente se tocarão em algum momento e lugar no futuro. Tornam-se, assim, possíveis e desejáveis "parcerias" - sem maiores disputas e conflitos - entre ambos os lados, setor público (governo) e setor privado (empresas).

É sintomática neste sentido a (con)fusão das siglas voltadas para o atendimento ao cidadão ou ao consumidor, não só aqui no Brasil mas em outros países; como é o caso do SAC Serviço de Atendimento ao Cidadão - que carrega a mesma sigla do Serviço de Atendimento ao Consumidor ou Cliente disponibilizado há alguns anos por diversas grandes empresas. Mesmo nos Estados Unidos ocorre tal coincidência entre o Citizen Relationship Management e o Customer Relationship Management.

Ausência de conflitos e presença pacífica de "agentes" aos quais se atribuiu, até então, lógicas distintas - mesmo por aqueles que apenas criticaram mais intrinsecamente as sociedades capitalistas (vide a lógica dos propagadores do neoliberalismo) - é um importante pressuposto para que a implementação das novas tecnologias seja considerada politicamente "neutra". Ao contrário, tendencialmente, deve-se permitir um melhor acesso àqueles que por razões diversas estiveram "afastados" (ou mesmo "excluídos") destes serviços. E isto se encontra explícito nas propostas governamentais ao afirmarem que "Não só o Brasil, mas todo o mundo, passa por transformações que envolvem a flexibilização dos modelos econômicos e o surgimento de um novo papel do Estado (...) O acompanhamento destas tendências exige planejamento e investimentos na revolução das telecomunicações, que possibilitem um ambiente de aumento da competitividade, agilidade e eficiência. Ao mesmo tempo ocorre um processo de exclusão cibernética que deve ser combatido com a universalização do acesso à informação e a ampliação da interatividade". ("Proposta de Política de Governo Eletrônico para o Poder Executivo Federal" in http://www.governoeletronico.gov.br, grifo nosso).

"Relação" ou "interação" têm como novo este caráter harmonioso, a complementaridade entre interesses, a aproximação entre pólos até então divergentes e sua expressão em parcerias que se apóiam na utilização das tecnologias capazes de quebrar velhas barreiras e divisões. Se há um problema, este se resume à questão do acesso que só pode ser realizado por intermédio de tecnologias que não estão à disposição de todos os "cidadãos". A questão de fundo sobre a relação governantes-governados, geralmente conflituosa, está sendo substituída pela preocupação com a acessibilidade à rede. Esta é uma preocupação pertinente quando compreendida dentro de um quadro maior das mudanças mais profundas que são origem e resultado, ao mesmo tempo, tanto das recentes políticas como das tecnologias telemáticas. A visão encurtada, que procuramos denunciar aqui apenas superficialmente, não só dá origem a uma aplicação equivocada das tecnologias, mas - o que é muito mais grave - sequer consegue enxergar e vislumbrar a realização do implícito "potencial emancipador" do qual fala.

Nossa reflexão visa, neste sentido, não apenas alertar criticamente a respeito de prováveis e dispendiosos fracassos destas tentativas, mas apontar algumas primeiras indicações a respeito de caminhos alternativos de apropriação das tecnologias que, ao nosso ver, oferecem uma chance maior para fortalecer o "diálogo" (numa aceitação mais dialética em termos de explicitação e

6 Por planejamento estratégico compreendemos um conjunto de medidas adotadas por governos, em diferentes níveis ou escalas com vistas a tornar seus lugares de governo (cidades, províncias ou países) competitivos globalmente. As proposições do planejamento estratégico surgiram no âmbito da administração de empresas, mas este termo foi consagrado na literatura social especializada por Manuel Castells e Jordi Borja. Para uma crítica mais consistente de algumas das proposições do planejamento estratégico vide LIMONAD e RANDOLPH, 2000. 
resolução de conflitos e disputas) mais democrático entre as partes.

Para ir mais fundo na compreensão do significado das tecnologias telemáticas e redes de computadores para uma possível transformação da relação entre Estado e sociedade é necessário "trabalhar" sua "relação" ou "interação".

$\mathrm{O}$ aprofundamento que procuramos exige um esforço em duas frentes: fugir da abstração vazia de uma mera tipologia de diferentes "agentes" ou seus relacionamentos - que não orienta a compreensão em direção à universalidade do fenômeno - como da singularidade empírica do caso que se perde numa (pseudo) complexidade de detalhes.

Não é uma posição "no meio" - entre dois pólos (abstrato versus concreto). Muito ao contrário: busca-se o reconhecimento da particularidade ("concreta", construída) de realidades no confronto de singularidades inscritas numa compreensão conceitual ("abstrata", também construída) das suas características gerais. Essas só se encontram por intermédio de um arcabouço teórico que permite o movimento de abstração sem cortar o retorno ao concreto que, assim, se revela como particular. Isto não significa que neste ensaio haverá espaço para uma explicitação mais profunda deste caminho ("método"); mas, mesmo quando ainda não inteiramente elaborado, ele será mais frutífero do que aquelas investigações que engessam seu "objeto" em parâmetros e critérios pretensamente exatos e claros - que raras vezes vão além do conhecimento do senso comum sofisticado.

O que não quer dizer que não contenham algum grão de verdade. O que foi observado mais empírica e, neste sentido, superficialmente a respeito dos três níveis da atuação das redes eletrônicas nas propostas de e-governo, pode ser compreendido no contexto mais genérico da articulação das vontades políticas em três patamares de acordo com Offe (1991). Para este autor (OFFE, 1991:128) os processos de articulação (política) entre governos/sistema político e as forças sociais podem "ser mais bem compreendidos, se os imaginamos compostos de três níveis ou três arenas de conflitos, dispostas uma sobre a outra". Acreditamos que a diferenciação entre o aproveitamento das novas tecnologias, interno ao sistema ( $1^{\circ}$ nível), entre o sistema governamental e a política $\left(2^{\circ}\right.$ nível) e a articulação entre forças sociais $\left(3^{\circ}\right.$ nível) pode nos fornecer, posteriormente, uma referência conceitual para uma leitura das propostas do e-governo.

Offe (1991:128 e ss) apresenta as três diferentes arenas da seguinte maneira:

a) a primeira e mais fácil de reconhecer é a arena dos processos políticos de decisões no interior do aparato estatal, cujos protagonistas são as elites políticas, que competem eleitoralmente e pelos escassos recursos; que decidem sobre programas político-sociais, legislação e orçamentos. "Este é o nível superficial e visível da política, aquele que chega às massas, e que sempre está em jogo, quando os cidadãos são instados a agir em seu papel político, como, por exemplo, no de eleitor" (OFFE. 1991, pp. 128s);

b) na medida em que o espaço disponível para as decisões das elites políticas é determinado por forças sociais, há um outro nível (subjacente ao anterior) onde se produz, distribui e institui o poder político. As mencionadas forças sociais, de forma bem menos visível, "influenciam as opiniões dos políticos e as suas percepções da realidade e, assim, as alternativas que estão abertas às decisões políticas e as conseqüências que podem ser esperadas de cada uma das alternativas". É nesta arena que se determina tanto a agenda política e prioridade relativa dos temas políticos, como as soluções dos problemas e a durabilidade dos pactos e compromissos. Apesar de uma certa intransparência na identificação de indivíduos que manipulam estas determinações, há "uma matriz do poder social, segundo a qual certas classes sociais, atores coletivos e outras categorias sociais têm chance maior do que outros para formar e mudar a realidade política e assim cunhar a agenda e o espaço das decisões das elites políticas." (OFFE, 1991, p. 129) A distribuição desigual dentro da estrutura social do acesso aos meios de produção, organização e comunicação e seu controle será aplicada, com diferentes graus de eficácia, 
para formar aquilo que os políticos visualizam como seu campo de decisão;

c) abaixo deste segundo nível da política, existe um terceiro no qual ocorrem as mudanças no interior da própria matriz social; são transformações que alteramos "pesos" relativos que os atores coletivos possuem na formação do campo de decisão (dos temas políticos); trata-se aqui das posições de poder social que são questionadas, objeto de mudanças e redistribuição. "O que ocorre no terceiro e mais importante nível da política, é a luta pela redistribuição do poder social. O poder do mercado, a legitimidade política ou a força de organização que um grupo ou uma classe usufrui, durante certo tempo, podem, por exemplo ser reduzidos (...), ou outro grupo pode abrir para si novos canais de influência, formar novas alianças ou conquistar posição hegemônica mediante referência a valores, ideais e visões novos (OFFE, 1991,p. 130).

$\mathrm{O}$ autor conclui sua reflexão com o alerta de que as inter-relações entre os três níveis não são estritamente hierárquicas, mas circulares: "embora o espaço de ação do primeiro nível ('política formal') seja em grande parte, determinado pela matriz do poder social ('segundo nível'), é ele próprio, capaz de facilitar e promover uma revisão das bases normativas e das interpretações da distribuição do poder social ('terceiro nível'). E, por isso, o palco da política democrática deveria ser concomitantemente considerado como determinado pelo poder social e como determinante dele" (OFFE, 1991, p. 131).

A "tradução" desta concepção de Offe em uma representação voltada para articular diferentes "poderes" na sociedade e no Estado pode, pelo menos numa primeira e ainda tentativa aproximação, mostrar as dificuldades implícitas nas propostas que visam um fortalecimento da sociedade civil - a luta contra novas formas de exclusão social (digital divide) — em relação aos poderes instituídos do Estado, apropriados pelos governos.

As três arenas, em termos da abordagem habermasiana (vide HABERMAS, 1997), correspondem a articulações específicas entre os níveis:

a) na primeira arena encontramos aquilo que Habermas chama de poder administrativo articulado com o poder político;

b) já na segunda arena, o poder político está articulado àquilo chamado por Offe de poder social que expressa de alguma forma a estratificação de uma sociedade (e pode, portanto, abranger também o poder econômico);

c) por um lado, Offe parece estar mais preocupado com os processos subjacentes à distribuição do poder social, sem com isto aprofundar-se ao nível de um outro poder que Habermas, recorrendo a Hannah Arendt, chama de poder comunicativo.

Parece-nos que na concepção de Habermas este último poder não necessariamente precisa da mediação dos poderes sociais e políticos para ser "administrativamente" - ao nível do poder administrativo - relevante e eficaz. Quer dizer que para Habermas uma verdadeira transformação pressupõe uma passagem direta da terceira à primeira arena. Em certa medida tendemos a concordar com Habermas, pois de que valeria a participação cívica se não estiver orientada para uma redistribuição do poder social? Mas para que haja uma possibilidade de sucesso, tal processo somente poderá ser desencadeado a partir de um movimento autônomo destas comunidades e não de iniciativas que venham de cima para baixo — ou seja, a partir de orientações gerais e diretrizes de organismos e instituições governamentais ou não governamentais, que acabam por minar ou frustrar iniciativas autônomas e o crescimento e desenvolvimento crítico que caminhem no sentido de reduzir a distância governo-sociedade.

Podemos elaborar, a partir destes esquemas conceituais, algumas reflexões acerca da possibilidade e das limitações do e-governo e das redes telemáticas contribuírem para o fortalecimento da sociedade civil, uma maior aproximação entre governo e sociedade ou mesmo a luta contra novas formas de exclusão social: 
a) no primeiro patamar (nível) a utilização da tecnologia enquanto instalação de um apoio genuinamente "governamental" (portanto e-governo como vimos acima na sua forma restrita) contribuirá, sem dúvida, a um fortalecimento de articulações dentro do poder administrativo e das articulações políticas dentro do próprio sistema político; vimos, nas experiências acima mencionadas e mesmo no caso brasileiro que uma grande parte das propostas estão localizadas (e presas) neste patamar; dentro de uma visão relacional, o fortalecimento da dinâmica dentro de um nível pode, provavelmente, enfraquecer os relacionamentos e permeabilidades entre diferentes patamares;

b) vimos, segundo, que ainda uma parte significativa das propostas a respeito do e-governo se preocupa exatamente com essa relação entre poder social e econômico e poder político-administrativo; procura-se aproveitar de um certo potencial "articulador" (interatividade) das tecnologias para facilitar a transição e transmissão entre o poder social e o poder administrativo. Imaginamos, sem querer fazer nenhuma análise particular de algum caso, que a apropriação da tecnologia pelo poder administrativo na forma de egoverno e pela "sociedade" na expressão de seu poder social e econômico atinge aqueles segmentos ("classes") que já ocupam um lugar privilegiado na sociedade (maior poder social em relação a outros segmentos, matriz do poder social). Portanto, pode se imaginar que o uso destas novas tecnologias pode mais reforçar estruturas de poder pré-existentes do que rompe-las ou permitir sua transformação;

c) finalmente, neste terceiro nível, nossa atenção se volta para processos de formação do poder comunicativo (transformações da matriz social). Parece um tanto difícil poder pressupor que a apropriação das novas tecnologias no e-governo possa reforçar, diretamente, a cidadania e o poder comunicativo na base de comunidades e grupos/segmentos sociais. Não podemos nos deixar seduzir. A proposta de emancipação comunitária, fortalecimento da cidadania e democratização do acesso à informação em implementação pela rede governo no Brasil, tem fortes raízes nas diretrizes do planejamento estratégico, inclusive integra o Programa Avança Brasil, que está direcionado para tornar o país competitivo e uma das metas neste sentido é transformar os brasileiros em consumidores eletrônicos.

Parece-nos que uma possível contribuição deve ser de caráter mais indireto no sentido de fornecer os meios e facilitar sua apropriação através de um esforço autônomo e de iniciativa própria daqueles segmentos sociais ou comunidades. Em termos tecnológicos pode-se esperar um fortalecimento muito mais a partir daquilo que hoje se costuma chamar de RECs — redes eletrônicas comunitárias — que têm sua origem numa dinâmica própria de comunidades ou de entidades associativas ou não governamentais que contribuem para o fortalecimento do poder comunicativo (Southern e Ramos, 2001). E, na medida em que este se torne suficientemente forte para exercer influência sobre o poder administrativo, parece plausível trabalhar com a hipótese de que o e-governo seja direcionado para fortalecer o já fortalecido poder social na medida em que abre novos canais de interlocução e influência.

Em síntese, o confronto entre os exemplos, casos e experiências acima apresentados com este primeiro e provisório esquema conceitual já nos alerta a respeito de uma série de promessas divulgadas em relação à implantação do e-governo. Essas promessas, em boa parte negligenciam os processos políticos e sociais que fazem parte intrínseca de nosso universo - e apostam, de forma otimista, em certos resultados que se tornam cada vez mais improváveis com o avanço da tecnologia. Sem querer desprezar o esforço e a boa vontade de uma parte dos pesquisadores que trabalha neste campo, devemos manter a cautela em relação aos efeitos sociais que podem ser provocados por estas tecnologias. 


\title{
CONSIDERAÇÕES SOBRE A INTERAÇÃO SOCIEDADE-ESTADO ATRAVÉS DAS REDES TELEMÁTICAS
}

Resumo: A meta deste ensaio é proceder a uma leitura crítica do papel e significado dos portais de governo eletrônico na atualidade em relação à superação (ou aprofundamento) de divisões sociais e espaciais existentes nas sociedades contemporâneas. $\mathrm{O}$ trabalho está organizado em três passos principais: primeiro é caracterizado, de forma descritiva, os principais elementos e constituintes do e-governo (i). A seguir são explicitadas as formas de disseminação do e-governo no mundo e no Brasil (ii). Finalmente, fazemos um primeiro esboço da nossa perspectiva a respeito deste objeto a partir de uma reflexão crítica das suas características e proposições (iii).

Palavras-chave: governo eletrônico, tecnologias de informação e comunicação.

\begin{abstract}
This essay aims to proceed a critical reading of the role and meaning of electronic government's portals at the present time concerning the overcome (or deepening) of contemporary societies actual social and spacial divisions. The paper is organized in three main steps: first we characterize, in a descriptive way, e-government's main elements and constituent (i). Afterwards e-government's spread forms throughout the world and Brazil are clarified (ii). Finally, we make a first sketch of our perspective regarding this object based on a critical reflection of its characteristics and propositions (iii).
\end{abstract}

Keywords: e-government; information and communication technologies.

\section{Bibliografia}

FINQUELIEVICH, S. (2001): Eletronic democracy - Buenos Aires e Montevideo. Cooperation South, no. 1, pp. 61-81

HABERMAS, J. (1997): Direito e democracia. Entre facticidade e validade. 2 vols. Rio de Janeiro: Tempo Brasileiro

LIMONAD, E. e RANDOLPH, R. (2000): Cidade, lugar e representação. Sua crise e apropriação ideológica num mundo de "urbanização generalizada". Anais do 6. Seminário de História da Cidade e do Urbanismo, Natal/RN

OFFE, C. (1991): Algumas contradições do Estado social moderno. In idem, Trabalho e sociedade. Problemas estruturais e perspectivas para o futuro da sociedade do trabalho, Vol II Perspectivas. Rio de Janeiro: Tempo Brasileiro, pp. 113-13 1

RANDOLPH, R. e LIMA, M. H. DE T. (2000): "Digital divide": reflexões sobre novas formas de exclusão social. GeografarES - Revista do Departamento de Geografia da UFES, Vitória/ES, v. 1, n. 1, junho, pp. 89-107

SANTOS, E. S. (2001): Reforma administrativa, atendimento ao público e cidadania -o caso do $S A C$ em Salvador. Dissertação de mestrado, defendida no Programa de Pós-Graduação em Planejamento Urbano e Regional - UFRJ, Rio de Janeiro.

SANTOS, M. (1996): A natureza do espaço. Técnica e tempo, razão e emoção. São Paulo: Hucitec.

SOUTHERN, B.C. E RAMOS, S.A. (2001): Redes comunitárias e apropriação de novas tecnologias de informação e comunicação no Brasil — o caso do Rio de Janeiro. In: Anais do IX Encontro Nacional da ANPUR (Associação Nacional de Pesquisa e PósGraduação em Planejamento Urbano e Regional), Rio de Janeiro: ANPUR, pp. 18041813

URLs consultadas

http://www.ac.gov.br (site oficial do governo do Estado do Acre)

http://www.amapa.gov.br (site oficial do governo do Estado do Amapá)

http://www.amcham.com.br/revista/367 (câmara americana de comércio)

http://www.aracaju.se.gov.br (site oficial de Aracajú)

http://www.bahia.ba.gov.br (site oficial do governo do Estado da Bahia)

http://www.belem.pa.gov.br (site oficial de Belém)

http://www.belohorizonte.mg.gov.br (site oficial de Belo Horizonte)

http://www.brasil.gov.br (site oficial do governo brasileiro) 
http://www.campogrande.ms.gov.br (site oficial de Campo Grande)

http://www.ceara.gov.br (site oficial do governo do Estado do Ceará)

http://www.cuiaba.mt.gov.br (site oficial de Cuiabá)

http://www.curitiba.pr.gov.br (site oficial de Curitiba)

http://www.ecitizen.gov.sg (site oficial do governo de Singapura)

http://www.es.gov.br (site oficial do governo do Estado do Espírito Santo)

http://www.firstgov.gov (site oficial do governo dos Estados Unidos)

http://www.fortaleza.ce.gov.br (site oficial de Fortaleza)

http://www.gdf.gov.br (site oficial do governo do Distrito Federal — Brasília)

http://www.gobiernoeletronico.gov.br (site oficial das propostas de governo eletrônico)

http://www.goiania.go.gov.br (site oficial de Goiânia)

http://www.goias.gov.br (site oficial do governo do Estado de Goiás)

http://www.governo.rj.gov.br (site oficial do governo do Estado do Rio de Janeiro)

http://www.ipdal.com.br (site oficial do governo do Estado de Alagoas)

http://www.joaopessoa.pb.gov.br (site oficial de João Pessoa)

http://www.ma.gov.br (site oficial do governo do Estado do Maranhão)

http://www.maceio.al.gov.br (site oficial de Maceió)

http://www.matogrosso.mtgovbr (site oficial do governo do Estado de Mato Grosso)

http://www.mg.gov.br (site oficial do governo do Estado de Minas Gerais)

http://www.ms.gov.br (site oficial do governo do Estado do Mato Grosso do Sul)

http://www.natal.rn.gov.br (site oficial de Natal)

http://www.pa.gov.br (site oficial do governo do Estado do Pará)

http://www.pb.gov.br (site oficial do governo do Estado da Paraíba)

http://www.pernambuco.gov.br (site oficial do governo do Estado de Pernambuco)

http://www.piaui.pi.gov.br (site oficial do governo do Estado do Piauí)

http://www.pmf.sc.gov.br (site oficial de Florianópolis)

http://www.pmm.am.gov.br (site oficial de Manaus)

http://www.portoalegre.rs.gov.br (site oficial de Porto Alegre)

http://www.poupatempo.sp.gov.br (portal de serviços do Estado de São Paulo)

http://www.pr.gov.br (site oficial do governo do Estado de Paraná)

http://www.prefeitura.sp.gov.br (site oficial de São Paulo)

http://www.prodepa.psi.br (portal de serviços do Estado de Pará)

http://www.recife.pe.gov.br (site oficial de Recife)

http ://www.redegobierno.gov.br (portal de serviços do governo federal)

http://www.rio.rj.gov.br (site oficial do Rio de Janeiro)

http://www.rn.gov.br (site oficial do governo do Estado do Rio Grande do Norte)

http://www.rondonia.ro.gov.br (site oficial do governo do Estado de Rondônia)

http://www.rr.gov.br (site oficial do governo do Estado de Roraima)

http://www.rs.gov.br (site oficial do governo do Estado do Rio Grande do Sul)

http://www.sacnet.ba.gov.br (portal de serviços do Estado de Bahia)

http://www.salvador.ba.gov.br (site oficial de Salvador)

http://www.saoluis.ma.gov.br (site oficial de São Luís)

http://www.saopaulo.sp.gov.br (site oficial do governo do Estado de São Paulo)

http://www.sc.gov.br (site oficial do governo do Estado de Santa Catarina)

http://www.se.gov.br (site oficial do governo do Estado de Sergipe)

http://www.to.gov.br (site oficial do governo do Estado de Tocantins)

http://www.ukonline.gov.uk (site oficial do Reino Unido)

http://www.uol.com.br/negociosexame/complementos/revista0003_2c.html

http://www.vitoria.es.gov.br (site oficial de Vitória) 